\title{
Importance of early audiologic assessment in distal renal tubular acidosis
}

This article was published in the following Dove Press journal:

International Medical Case Reports Journal

22 December 2010

Number of times this article has been viewed

\author{
Anand P Swayamprakasam' \\ Elizabeth Stover \\ Elizabeth Norgett ${ }^{\prime}$ \\ Katherine G Blake-Palmer' \\ Michael J Cunningham ${ }^{2}$ \\ Fiona E Karet ${ }^{\prime}$ \\ 'Department of Medical Genetics, \\ Cambridge Institute for Medical \\ Research, Cambridge, UK; \\ ${ }^{2}$ Department of Otolaryngology, \\ Massachusetts Eye and Ear Infirmary, \\ Boston, MA, USA
}

\begin{abstract}
Autosomal recessive distal renal tubular acidosis is usually a severe disease of childhood, often presenting as failure to thrive in infancy. It is often, but not always, accompanied by sensorineural hearing loss, the clinical severity and age of onset of which may be different from the other clinical features. Mutations in either ATP6V1B1 or ATP6V0A4 are the chief causes of primary distal renal tubular acidosis with or without hearing loss, although the loss is often milder in the latter. We describe a kindred with compound heterozygous alterations in ATP6V0A4, where hearing loss was formally diagnosed late in both siblings such that they missed early opportunities for hearing support. This kindred highlights the importance of routine audiologic assessments of all children with distal renal tubular acidosis, irrespective either of age at diagnosis or of which gene is mutated. In addition, when diagnostic genetic testing is undertaken, both genes should be screened irrespective of current hearing status. A strategy for this is outlined.
\end{abstract}

Keywords: sensorineural hearing loss, renal tubular acidosis, recessive, genetics, mutation

\section{Introduction}

Autosomal recessive distal renal tubular acidosis (dRTA) is usually a severe disease of childhood, which most often presents as failure to thrive in infancy or systemic upset, with vomiting and/or dehydration in the context of intercurrent illness. The fundamental defect in dRTA is an inability of the kidneys to remove the daily metabolic load of excess nonvolatile acid, which is necessary to maintain normal systemic $\mathrm{pH}$ close to 7.4. Although both proximal and distal nephron segments are involved in the strict homeostatic control of acid-base balance, fine regulation falls to the collecting duct, where a combination of urine acidification and bicarbonate generation is carried out by alpha-intercalated cells. Functional failure of this cell type leads to the cardinal features of normal anion gap metabolic acidosis accompanied by inappropriately alkaline urine (always $>5.5$ ). Prior to treatment, dRTA is almost always accompanied by hypokalemia, calcification of the renal tract (either nephrocalcinosis, stone formation, or both), and metabolic bone disease. ${ }^{1}$ The exact mechanism for the hypokalemia is unclear. Secondary activation of the renin/aldosterone system as well as increased potassium secretion to maintain electrical neutrality have been postulated as the responsible mechanisms. Hypocitraturia, together with alkaline urinary $\mathrm{pH}$, is believed to be responsible for the renal tract calcification. Urinary citrate is low in dRTA because citrate reabsorption by the proximal tubule is upregulated to provide new bicarbonate. Long-standing acidosis leads to bone thinning, which presents as rickets in children. In addition, some, but not all, patients with recessively inherited 
dRTA have progressive bilateral sensorineural hearing loss (SNHL). ${ }^{2}$ Failure of $\mathrm{pH}$ homeostasis in the cochlea is believed to be the responsible mechanism.

Many of the problems associated with dRTA can be minimized by prompt diagnosis and treatment, usually with alkali therapy, such as potassium citrate. However, although this serves to correct the biochemical abnormalities, improve health, and reduce the incidence and/or progression of renal tract calcification, rickets, and hypokalemic muscle weakness, ${ }^{3,4}$ it cannot prevent the onset or progression of SNHL, ${ }^{5}$ probably because of the anatomic isolation of the cochlea.

Aside from the very few affected kindreds from South East Asia segregating two mutations in SLC4A1 (encoding the chloride bicarbonate exchanger AE1), all reported mutations associated with recessive dRTA affect one of two genes, ie, ATP6V0A4 or ATP6V1B1..$^{6-9}$ These genes encode the a4 and $\mathrm{B} 1$ subunits of $\mathrm{H}^{+}$-ATPase and, of the major organs, both are expressed only in the kidney. $\mathrm{H}^{+}$-ATPases are multisubunit pumps that are essential for the acidification of various intracellular compartments, as well as pumping protons across the plasma membranes of a number of different cell types. In addition to the distal renal intercalated cell, the function of which is summarized above, these cell types include cells in the inner ear, osteoclasts, and male genital tract. ${ }^{6,8,10}$ The $\mathrm{H}^{+}$-ATPase located at the apical surface of renal intercalated cells is the one containing a4 and B1 subunits, rather than their ubiquitously expressed counterparts a1 and B2 (Figure 1). Hence, individuals who have inherited mutations in either ATP6V0A4 or ATP6V1B1 are unable to acidify urine, leading to often severe acidosis with arterial $\mathrm{pH}<7.2^{6-8}$ Initial studies suggested that mutations in $A T P 6 V 1 B 1$ resulted in recessive dRTA with SNHL, whereas mutations in ATP6V0A4 allowed for preserved hearing. ${ }^{6,7}$ Subsequently, a4, like B1, was found to be expressed within the inner ear, and mutations in ATP6VOA4 are now known to occur in some recessive dRTA kindreds with SNHL. ${ }^{8,9}$ The kindred investigated here highlights the importance of routine audiologic assessments of all children with recessive or apparently sporadic dRTA, irrespective either of age at diagnosis or of which gene is mutated. In addition, when diagnostic genetic testing is undertaken, both the $\mathrm{H}^{+}$-ATPase genes should be screened, irrespective of current hearing status. A strategy for this is outlined.

\section{Case reports}

A 14-year-old girl and her younger brother, from a family of Armenian-Turkish descent, were referred for genetic
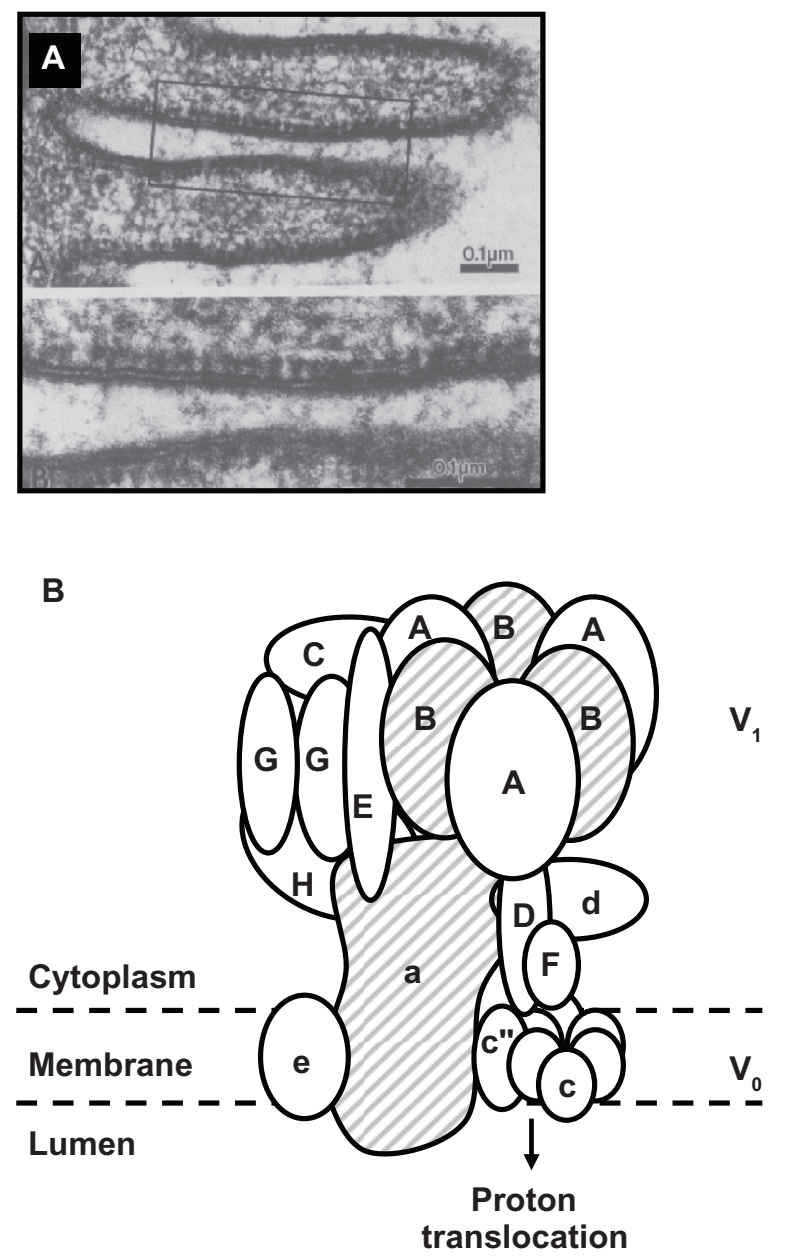

Figure I The distal nephron apical $\mathrm{H}^{+}$ATPase. Although the multisubunit $\mathrm{H}^{+}$ATPase is ubiquitously expressed, a specialized version is found at high density at the apical (urinary) surface of intercalated cells, mostly in the collecting duct. A) This type of pump is studded along the plasma membrane in an electron micrograph of the turtle urinary system (image courtesy of Professor P Steinmetz). B) General structure of $\mathrm{H}^{+}$ATPases. In the kidney, the $B$ and a subunits (hatched) are composed of the genetically distinct $\mathrm{BI}$ and $\mathrm{a} 4$ forms, whereas generic intracellular pumps contain B2 and al subunits.

investigation of dRTA with bilateral SNHL. The initial clinical scenario has been described elsewhere. ${ }^{2}$ Briefly, a febrile episode with weight loss and hypokalemic metabolic acidosis at 10 weeks of age in the index case prompted the diagnosis of dRTA by a pediatrician. Her brother presented with a similar biochemical picture at five months, but with growth retardation. The kindred was defined as recessive because both parents were clinically and biochemically unaffected, were not related, but had two affected offspring. Once the diagnoses of dRTA were confirmed, systemic alkali therapy and potassium supplementation were commenced in both children. Both have grown to just below the 10th percentile, which approximates parental height. Nephrocalcinosis is not prominent in either.

In both these children there were features suggestive of hearing impairment from an early age. It was noted that the 
girl progressively increased the volume of the television, radio, and her own speech, and that the boy had nasal speech, which results from impaired accuracy of palatal obstruction during the production of non-nasal sounds, leading to increased nasal resonance. Unfortunately, bilateral SNHL was not formally diagnosed using pure-tone audiometry until the ages of 10 and 13 years, respectively. At that time, otologic examination and radiologic investigation revealed no abnormalities of middle or inner ear structures. The SNHL of both children was thereafter managed using bilateral hearing aids, in conjunction with communication and education enhancement. The genetic basis for dRTA was not yet known during this period.

\section{Genetic studies}

Genetic studies were conducted with ethics committee approval and written informed consent from the parents. Because recessively inherited dRTA is genetically heterogeneous, simple analysis of possible linkage to either known locus was first conducted to try to exclude one or the other. Previously identified intragenic biallelic single nucleotide polymorphisms that function as restriction fragment length polymorphisms in ATP6V0A4 (three) and in ATP6V1B1 (four) were used. ${ }^{8}$ Polymerase chain reaction-amplified products of the relevant exons were digested with appropriate enzymes (see Table 1) and resolved by agarose gel electrophoresis, and the resulting genotypes were used to construct haplotypes. Evidence for linkage to ATP6V0A4 and/or ATP6V1B1 was considered likely if the haplotypes of the affected offspring were identical by descent, and possible if identical by state.

As displayed in Figure 2A and B, linkage could not be excluded to either of these loci because the children were haploidentical at both (by state at ATP6VOA4 and by descent at ATP6V1B1). Therefore, both genes were screened for mutations by DNA sequencing of all coding exons and exon-intron boundaries. No sequence variations other than known single nucleotide polymorphisms were detected in ATP6V1B1. However, in both cases, the same two heterozygous mutations were detected in exon 22 of ATP6VOA4; 2308C > T (R770X) and 2420G > A (R807Q). Representative sequence traces are shown in Figure $2 \mathrm{C}$. Only once has either mutation previously been identified in dRTA kindreds, in each case as a homozygous alteration in a single kindred..$^{8,9}$ DNA sequencing of both parents in the present family confirmed that the two mutations had been inherited in trans by both children (Figure 2C).

In codon 770, the replacement of an arginine residue with a premature stop codon that truncates the protein by 72 amino acids is likely to result in a loss of functional protein. In codon 807 , the loss of positive charge by substitution of glutamine for arginine could alter protein structure or stability and therefore function, and we have shown elsewhere that a yeast model of this mutation results in dramatically lower protein levels. ${ }^{10}$

\section{Discussion}

dRTA is usually a severe disease of childhood, with a wide spectrum of clinical features. Hearing impairment is a common, but not invariant, accompaniment of recessive disease, occurring in about $80 \%$ of our initial genetically analyzed cohort. $^{6-8}$ It is not found where $S L C 4 A 1$ is the causative dRTA gene, because SLC4A1 is not expressed in the inner ear. Hearing loss may develop contemporaneously with, before, or much later than the systemic acidosis. There is also considerable variability in its severity, which may not mirror the course of the acidosis. ${ }^{6,8,9}$ In addition, widened vestibular aqueducts may occasionally be found on detailed cranial imaging. ${ }^{11,12}$ In this report, we present genetic findings in two siblings whose dRTA was diagnosed at an early age,

Table I Details of restriction fragment length polymorphisms used in this study

\begin{tabular}{|c|c|c|c|c|}
\hline $\begin{array}{l}\text { Single nucleotide } \\
\text { polymorphism }\end{array}$ & Site & $\begin{array}{l}\text { Amino acid position } \\
\text { and change }\end{array}$ & Enzyme & $\begin{array}{l}\text { PCR product sizes } \\
\text { before } \rightarrow \text { after digest (bp) }\end{array}$ \\
\hline \multicolumn{5}{|l|}{ ATP6V0A4 } \\
\hline rs10258719 & Exon 3 & $\mathrm{~A} 2 \mathrm{~V}$ & $B g \|$ & $299 \rightarrow 149+150$ \\
\hline rsI026435 & Exon 16 & F554F & $X \mathrm{cml}$ & $262 \rightarrow 157+105$ \\
\hline rs3807I54 & Exon 17 & $\mathrm{H} 604 \mathrm{H}$ & BsaAl & $323 \rightarrow 174+149$ \\
\hline \multicolumn{5}{|l|}{ ATP6VIBI } \\
\hline rs2266918 & Exon 2 & S46S & TspRI & $282 \rightarrow 123+159$ \\
\hline rs967063 & Intron 3 & & HруCH4IV & $470 \rightarrow 237+233$ \\
\hline$*$ & Exon 6 & EI6I K & Aval & $251 \rightarrow 66+185$ \\
\hline rs2072462 & Exon 10 & R334R & BstUI & $267 \rightarrow 120+147$ \\
\hline
\end{tabular}

Note: *ATP6VIBI exon 6 single nucleotide polymorphism is novel.

Abbreviations: PCR, polymerase chain reaction; bp, base pairs. 
A

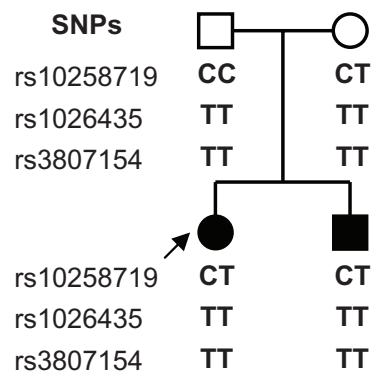

B

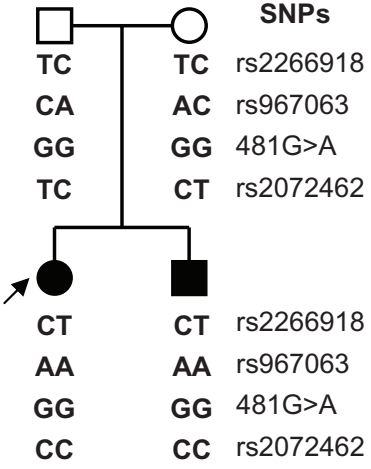

C

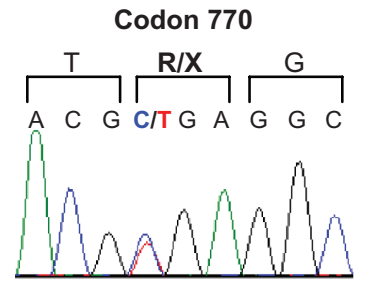

Children \& father

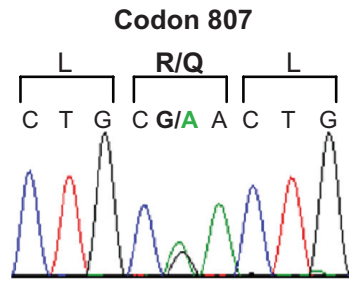

Children \& mother
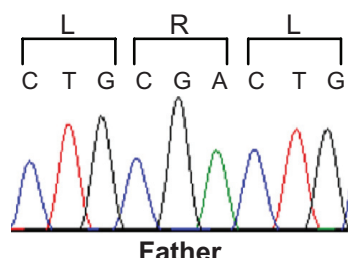

Figure 2 Genotyping of kindred. Single nucleotide polymorphisms in A) ATP6VOA4 and in B) ATP6VIBI were subject to polymerase chain reaction amplification followed by specific restriction digestion, and this was used to assess linkage to both genes. Details of these single nucleotide polymorphisms are shown in Table I. Filled symbols are affected individuals whereas unfilled symbols are unaffected individuals. Arrow denotes index case. C) Mutations in ATP6VOA4 were identified by DNA sequencing. Upper traces are representative of the heterozygous alterations in codon 770 and 807 in both children and one affected parent. Lower traces show wild-type sequences from the unaffected parent. Translation products of the sense strand are shown, with altered products in color. In codon 770 , the $C>T$ transition introduces a premature stop codon. In codon 807 , the G $>$ A transition results in the substitution of glutamine for arginine.

but where SNHL was not documented until later, even though some clinical features suggestive of hearing impairment were present from an early age. With improved surveillance, such children could have measures instituted to improve their hearing at a younger age, which might reduce the impact of SNHL on language, education, and social development, a point emphasized in previous reports but not necessarily routinely performed..$^{13}$ Conversely, the situation may arise whereby hearing loss is observed but acidosis is mild and potentially missed. ${ }^{11}$ It is therefore prudent to consider dRTA among the differential diagnoses where SNHL is found in childhood or adolescence.
Both hearing aids and cochlear implants have been found to be successful in the management of SNHL in children with dRTA. For example, a study of children with severe to profound SNHL who received cochlear implants showed that they performed significantly better on tests of spoken language than those with hearing aids, but that hearing aids were equally as effective as implants in children where SNHL was only mild to moderate. ${ }^{14}$ However, given the surgical risks and potential adverse effects, cochlear implants are recommended in severe to profound SNHL only, or where hearing aids are no longer effective.

Because SNHL may not be clinically evident at the time of diagnosis of dRTA, and because it progresses despite treatment, every child presenting with dRTA should be offered early and serial audiologic assessment. This kindred also has important implications for diagnostic genetic screening, because the early conclusion of an association between SNHL and one particular disease-causing gene ${ }^{6,7}$ has not been borne out by subsequent genetic investigation. ${ }^{8,9}$ Thus, in situations where diagnostic genetic screening is available, the hearing status of the child should not a priori influence a decision about which of the genes to screen. In addition, because mutations in ATP6VOA4 do not preclude children with dRTA from developing later SNHL, finding such mutations should not preclude ongoing attempts to diagnose and treat any SNHL.

\section{Acknowledgment}

This research was supported by the Wellcome Trust (Senior Fellowship 054531 to FEK) and the National Institute for Health Research Cambridge Biomedical Research Centre, Cambridge, UK.

\section{Disclosure}

The authors report no conflicts of interest in this work.

\section{References}

1. Karet FE. Inherited distal renal tubular acidosis. JAm Soc Nephrol. 2002; 13(8):2178-2184.

2. Brown MT, Cunningham MJ, Ingelfinger JR, Becker AN. Progressive sensorineural hearing loss in association with distal renal tubular acidosis. Arch Otolaryngol Head Neck Surg. 1993;119(4):458-460.

3. Rothstein M, Obialo C, Hruska KA. Renal tubular acidosis. Endocrinol Metab Clin North Am. 1990;19(4):869-887.

4. Sharma AP, Singh RN, Yang C, Sharma RK, Kapoor R, Filler G. Bicarbonate therapy improves growth in children with incomplete distal renal tubular acidosis. Pediatr Nephrol. 2009;24(8):1509-1516.

5. Zakzouk SM, Sobki SH, Mansour F, al Anazy FH. Hearing impairment in association with distal renal tubular acidosis among Saudi children. J Laryngol Otol. 1995;109(10):930-934.

6. Karet FE, Finberg KE, Nelson RD, et al. Mutations in the gene encoding $\mathrm{B} 1$ subunit of $\mathrm{H}^{+}$-ATPase cause renal tubular acidosis with sensorineural deafness. Nat Genet. 1999;21(1):84-90. 
7. Smith AN, Skaug J, Choate KA, et al. Mutations in ATP6 N1B, encoding a new kidney vacuolar proton pump $116-\mathrm{kD}$ subunit, cause recessive distal renal tubular acidosis with preserved hearing. Nat Genet. 2000;26(1):71-75.

8. Stover EH, Borthwick KJ, Bavalia C, et al. Novel ATP6V1B1 and ATP6VOA4 mutations in autosomal recessive distal renal tubular acidosis with new evidence for hearing loss. J Med Genet. 2002;39(11): 796-803.

9. Vargas-Poussou R, Houillier P, Le Pottier N, et al. Genetic investigation of autosomal recessive distal renal tubular acidosis: Evidence for early sensorineural hearing loss associated with mutations in the ATP6VOA4 gene. J Am Soc Nephrol. 2006;17(5):1437-1443.

10. $\mathrm{Su}$ Y, Blake-Palmer KG, Sorrell S, et al. Human $\mathrm{H}^{+}$ATPase a4 subunit mutations causing renal tubular acidosis reveal a role for interaction with phosphofructokinase-1. Am J Physiol. 2008;295(4):F950-F958.
11. Joshua B, Kaplan DM, Raveh E, Lotan D, Anikster Y. Audiometric and imaging characteristics of distal renal tubular acidosis and deafness. J Laryngol Otol. 2008;122(2):193-198.

12. Andreucci E, Bianchi B, Carboni I, et al. Inner ear abnormalities in four patients with dRTA and SNHL: Clinical and genetic heterogeneity. Pediatr Nephrol. 2009;24(11):2147-2153.

13. Batlle D, Ghanekar H, Jain S, Mitra A. Hereditary distal renal tubular acidosis: New understandings. Annu Rev Med. 2001;52:471-484.

14. Geers AE. Comparing implants with hearing aids in profoundly deaf children. Otolaryngol Head Neck Surg. 1997;117(3):150-154.

\section{Publish your work in this journal}

The International Medical Case Reports Journal is an international, peer-reviewed open-access journal publishing original case reports from all medical specialties. Previously unpublished medical posters are also accepted relating to any area of clinical or preclinical science. Submissions should not normally exceed 2,000 words or
4 published pages including figures, diagrams and references. The manuscript management system is completely online and includes a very quick and fair peer-review system, which is all easy to use. Visit http://www.dovepress.com/testimonials.php to read real quotes from published authors.

Submit your manuscript here: http://www.dovepress.com/international-medical-case-reports-journal-journal 